\title{
High Quality Development of Comprehensive University Medical Education In China: Problems And Path In The New Era
}

Shaochun Lv

Jiamusi University

Hanjun Song

Jiamusi University

Lulu Cheng (D1184605395@qq.com)

China University of Petroleum

\section{Research Article}

Keywords: Comprehensive university, Medical education, High quality development, Reform, Thinking

Posted Date: November 23rd, 2021

DOI: https://doi.org/10.21203/rs.3.rs-1054816/v1

License: (c) This work is licensed under a Creative Commons Attribution 4.0 International License.

Read Full License 


\section{Abstract}

Background: In the new era, the situation of medical education in China has undergone significant and profound changes. Medical universities not only carry the historical mission of providing multidisciplinary talent support for the modernization of education, but also are endowed with the tasks and requirements of holding high quality medical education and promoting the construction of Health China. Objective To state the theory of medical education in the new era, this paper analyzes the problems existing in medical education of China's comprehensive universities, and gives the countermeasures and ideas of medical education development.

Method: By using literature research, illustrating with examples, conclusion and reasoning methods to analyze and illustrate.

Result: This paper interprets the connotation of high-quality development of medical education in the new era, thinks about the current situation features of domestic medical education such as the multilateral exploration of management mode of comprehensive university medical education, lists the main problems in medical education, and discusses the ideas and countermeasures to solve these problems in the future.

Conclusion: The reform and development of medical education need to further improve the top-level design, and obtain the understanding and support from stakeholders. The comprehensive university should consider putting medical personnel training in the vision of Health China construction. Under the guidance of the national macro policy of holding high-level undergraduate education, it is imperative to persist in problem-oriented principle and make efforts to reform, using information technology to promote the sharing of educational resources among schools and form a synergy in medical education.

\section{Background}

Since the 2017 national conference of medical education reform and development, China has issued a series of standards and documents focusing on the realization of the goals of "China Education Modernization 2035" and "Health China 2030". In October 2018, the Ministry of Education issued "Opinions on speeding up the construction of high-level undergraduate education to comprehensively improve the ability of personnel training". At the beginning of 2019, the CPC Central Committee and State Council issued "China Education Modernization 2035", and a series of documents such as the implementation plan for accelerating the modernization of education (2018-2022) were issued by the General Office of the CPC Central Committee and the State Council, all profoundly reflecting the high attention paid by the state to the development of undergraduate education including medical education in the new era[1-3]. There are 156 undergraduate medical schools in China, including 76 comprehensive universities, accounting for nearly half of the total, and it plays an important role in the field of medical education. As an indispensable subject of medical education, comprehensive universities should shoulder the dual mission of providing talent to support social development and the construction of 
Health China. Therefore, this paper expounds the connotation of high-quality development of medical education in the new era, analyzes the situation characteristics and existing problems of medical education from the perspective of comprehensive universities, and puts forward the reform ideas and countermeasures in the future which is helpful to explore the effective path of high-quality development of medical education in China[4].

\section{Understanding Of The Connotation Of High Quality Development Of Medical Education In The New Era}

The report of the 19th National Congress of the Communist Party of China points out that "the new era is an era of connecting the past with the future, carrying forward the past and opening up the future, and continuing to win the great victory of socialism with Chinese characteristics under the new historical conditions. It is an era of decisive victory in building a moderately prosperous society in an all-round way, and then building a modern power in all respects. It is an era in which people of all ethnic groups working together, constantly creating a better life, and gradually realizing the common prosperity for all. The era of prosperity is an era in which all Chinese people work together to realize the "Chinese Dream". It is an era in which China is increasingly approaching the center of the world stage and constantly making greater contributions to mankind" [5]. From the perspective of medical education, the understanding of the new era can focus on a series of important keywords emerging in recent years, such as Medicine-education Coordination, Health China, New Medicine Subject, Excellent Doctor Plan, and so on. All of these keywords reflect the characteristics of the new era and the mission of medical education.

However, the current level of health services in China cannot meet the people's health needs with the continuous improvement of economic and social development. The shortage and uneven distribution of high-quality health resources have become the concrete embodiment of the main social contradictions in the field of health in the new era. The report of the 19th National Congress of the Communist Party of China puts forward the requirements for the reform and development of education and health care from the aspects of education and health strategy. Therefore, medical education must actively focus on the people's yearning for a better life of high-quality education and high-quality health services, strive to achieve high-quality development, and better meet people's diverse and multi-faceted needs.

The connotation of high-quality development theory comes from the characteristics of the new era and the practice of China's economic and social development, and high-quality development is the development that embodies the new concept of development in the new era. To promote the high-quality development of medical education is not only the fundamental embodiment of implementing the new development concept and the spirit of the national education conference, but also the active choice to adapt to the change of medical model and the reform of China's health system. It is also the way to hold high-level undergraduate education and realize the modernization of education. The goal should be in line with the needs of the transformation of medical education. For comprehensive universities, we should not only fully understand the significance and connotation of promoting the high-quality development of medical education, but also actively hold high-level undergraduate education, create 
"Golden Class" of medical education, and promote the implementation of Medicine-education coordination task. What's more, it is imperative to actively participate in the three-level certification of medical education, and improve the quality of medical education so as to strengthen and improve the quality of medical education.

\section{Analysis On The Characteristics Of Current Medical Education Situation}

\subsection{Exploration on the management mode of medical education in Comprehensive Universities}

The General Office of the State Council proposed in document No.63(2017) that deepening the reform of medical education management system in comprehensive universities should be implemented as an important measure, but the system reform belongs to the category of superstructure, which cannot be completed or improved overnight. Although some domestic scholars have classified and sorted out the medical education management models of comprehensive universities, the models of each university have not been completely finalized and are still in the process of adjustment, therefore, these categories can only represent the reform achievements of the past period. It is worth noting that in recent years, comprehensive universities have continued making efforts in medical education. Through selfconstruction, merger and co-construction, they have set up relevant institutions and carry out medical education or scientific research, such as Tianjin University, Harbin Institute of Technology, China University of Science and Technology, etc. (as shown in Table 1). In fact, it is not uncommon for comprehensive universities to run medical institutions abroad. Many famous universities in developed countries have set up medical institutions, such as Harvard University, Cambridge University, McMaster University, Tokyo University, etc. It can be seen that more and more comprehensive universities realize that medical education plays a very significant role in helping schools to enhance the overall strength of running schools. In addition, by the end of 2018, Shanghai Medical College of Fudan University and its six affiliated hospitals has become a highlight of the joint efforts of government and university to promote the reform of medical education management system. Of course, whether this model is feasible for a long time and whether it can be promoted in other universities still needs to be tested by practice[68]. 
Table 1

Addition medical education or scientific research agencies in China's comprehensive universities from 2016 to 2021

\begin{tabular}{|c|c|c|c|}
\hline Year & School Name & Addition Agency & Affiliation \\
\hline 2016 & $\begin{array}{l}\text { Beijing University of } \\
\text { Aeronautics and } \\
\text { Astronautics }\end{array}$ & $\begin{array}{l}\text { Medical Engineering Cross } \\
\text { Innovation Research Institute }\end{array}$ & $\begin{array}{l}\text { Ministry of Industry and } \\
\text { Information Technology }\end{array}$ \\
\hline \multirow[t]{3}{*}{2017} & $\begin{array}{l}\text { University of Science and } \\
\text { Technology of China }\end{array}$ & $\begin{array}{l}\text { Department of Life Sciences and } \\
\text { Medicines }\end{array}$ & Ministry of Education \\
\hline & Shandong University & Qilu Medical College (renamed) & Ministry of Education \\
\hline & $\begin{array}{l}\text { Northwest University of } \\
\text { Technology }\end{array}$ & Medical Research Institute & $\begin{array}{l}\text { Ministry of Industry and } \\
\text { Information Technology }\end{array}$ \\
\hline \multirow[t]{4}{*}{2018} & Tianjin University & Department of Medicine & Ministry of Education \\
\hline & $\begin{array}{l}\text { Harbin Institute of } \\
\text { Technology }\end{array}$ & School of medicine and health & $\begin{array}{l}\text { Ministry of Industry and } \\
\text { Information Technology }\end{array}$ \\
\hline & Chongqing University & $\begin{array}{l}\text { Institute of advanced medical } \\
\text { research }\end{array}$ & Ministry of Education \\
\hline & Northeatern University & $\begin{array}{l}\text { College of medical and } \\
\text { bioinformatics Engineering (co } \\
\text { construction) }\end{array}$ & Ministry of Education \\
\hline 2019 & $\begin{array}{l}\text { East China Normal } \\
\text { University }\end{array}$ & $\begin{array}{l}\text { Institute of Medicine and Health } \\
\text { research }\end{array}$ & Ministry of Education \\
\hline 2020 & Shanghai University & $\begin{array}{l}\text { Institute of Medical and Industrial } \\
\text { Intersection }\end{array}$ & Shanghai city \\
\hline \multirow[t]{2}{*}{2021} & Linyi University & Medical School & Shandong Province \\
\hline & $\begin{array}{l}\text { Chinese University of } \\
\text { Hong Kong (Shenzhen) }\end{array}$ & Shenzhen Medical School & CUHK and Shenzhen city \\
\hline
\end{tabular}

\subsection{Integrating the concept of three-level certification into professional teaching quality monitoring}

Teaching quality monitoring and accreditation play an irreplaceable role in ensuring the quality of medical education. In the second half of 2018, the Ministry of Education set up the "Research Group on Monitoring Indicators of Teaching Quality of Clinical Medicine" to organize medical education experts including comprehensive universities to discuss and formulate the monitoring indicator system (core indicators) of teaching quality in many rounds, so as to promote the national level of teaching quality monitoring. It is worth noting that by the end of 2020, 106 medical colleges and universities in China have accepted the clinical medicine accreditation of the Ministry of Education. From the feedback data of the accreditation institutions, the accreditation work has achieved remarkable results. In 2020, the National 
Medical Education Development Center of Peking University conducted a survey on 74 domestic medical schools that have passed the clinical medicine professional accreditation. The results showed that $90.5 \%$ $(67 / 74)$ of the certified colleges and universities were generally satisfied with the accreditation work, and the rest were satisfied. It was thought that the preliminary report of the accreditation expert group pointed out the key problems of the school. In the future, according to the concept of three-level certification, how to combine the professional teaching quality monitoring with the current professional accreditation system is a key problem to be solved in medical education research.

\subsection{Medical education think tank alliances have been established}

At present, with the development of new think tanks and the sharing of intellectual resources, medical schools need to take advantage of the situation and establish a think tank alliance with multi school cooperation, so as to promote the high-quality and large-scale development of medical education. In July 2014, the Sino Russian Medical University Alliance, which was jointly participated by 92 Chinese and Russian medical universities, was established in Harbin Medical University, setting up a new bridge for Sino Russian medical and health cooperation. In April 2015, the Northwest Medical Education Alliance, including 32 Medical Colleges and relevant units, was established in Xi'an. The organization has built a medical education cooperation platform in the western region of China, which is helpful to promote the collaborative innovation of medical scientific research in Northwest China. China Medical Education MOOC alliance was established in Beijing in March 2014, which promoted the organic integration of MOOC platform construction and school medical education, and taking into account the needs of post graduation medical education and primary health personnel training. In May 2018, "One belt and one Road" International Medical Education Alliance was founded in China Medical University, and the medical education institutions participating in the alliance were from 15 countries. In December 2018, 9 "Double First-class Construction" universities including Peking University jointly established the medical "Double First-class" construction alliance, aiming to build a high-end think tank serving the medical "double firstclass construction". These new think tanks have also attracted the participation of many comprehensive universities, which has played a important role in updating the concept of medical education and accelerating the process of internationalization of medical education in China.

\subsection{Integrated medical education came into being}

In recent years, with the integration of medicine and other disciplines, the original medical disciplines are too detailed and fragmented. It is easy to lead them to "see the trees but not the forest" in the process of learning, which is not conducive to the formation of systematic clinical thinking of medical students, and it is difficult to cultivate high-quality applied medical talents. Therefore, in recent years, integrated medical education came into being. In April 2017, academician Fan Daiming initiated the Integrated Medical Education Branch of China Medical Education Association, and proposed the goal of gradually establishing an integrated medical education system suitable for China's basic national conditions. In 2017, China Integrated Pharmacy Alliance was established in Guangdong Pharmaceutical University, aiming to lead the national counterparts to study drugs and carry out teaching with the concept of 
integrated pharmacy. At present, more and more medical and pharmaceutical colleges are committed to promoting the substantive integration of medical education. In 2018, the Medical Department of Tianjin University was established to implement the combination of medical and engineering, and explore the "Tianda Mode" of medical development. In addition, Zhejiang University has set up a communication platform for the combination of medicine, industry and information technology, which is guided by clinical problems and by means of engineering technology and information technology, creating a network sharing space for experts with multi-disciplinary background to communicate. Therefore, It is a logical thing for comprehensive universities to rely on the inherent advantages of interdisciplinary integration to carry out integrated medical education [9-11].

\section{Problems Of Medical Education In Comprehensive Universities}

\subsection{The implementation of the policy of medical education collaboration is not in effective in some places}

According to the requirements of the national medical education coordination strategy, China will accelerate the construction of a clinical medical personnel training system with " $5+3$ " as the main body, and " $3+2$ " as the supplement. In accordance with the Five Development Concepts of "innovation, coordination, green, open and sharing", the implementation of medical education cooperation in the new era to promote the high-quality development of medical education not only needs to make the top-level design in the nation, but also needs to strengthen the supervision on "coordination", so that all localities can promote and implement it cooperatively, avoiding a dead letter and long-term delay. In recent years, it is found that in the specific implementation process, some medical schools are inconsistent in pace, lacking of supporting special supervision and evaluation program of medical education cooperation. At the national level, there is no organization to implement the special supervision of medical education cooperation, which may lead to the inaction or slow action of some localities and medical colleges, and the implementation of various policies will eventually become distant, including some comprehensive universities.

\subsection{The management system and operation mechanism of medical education are not perfect}

(1)The management mechanism of universities, medical schools and affiliated hospitals has not been straightened out. Some medical schools in comprehensive universities no longer have the status of legal person, which affects the efficiency of teaching, scientific research and medical management, and makes it more difficult to coordinate medical teaching and research. (2) Lack of scientific planning for the establishment of medical schools. In recent years, comprehensive universities have set up medical schools one after another. Whether the national level needs to make a unified plan for the establishment of medical schools is an urgent problem to be solved in the development of medical education. (3) The coordination of the relationship between rescuing the wounded and educating students. Under the situation of deepening medical reform, affiliated hospitals should not only maintain the public welfare attribute of public hospitals, but also ensure that their profit income does not decline. It has not yet found 
a balance between the urgency of responding to the social demand for medical services and the importance of medical personnel training. The phenomenon of emphasizing medical treatment over teaching has existed for a long time in some places, which promotes the construction of university disciplines and the construction of specialized departments in affiliated hospitals. The proposed integration measures are not effective enough.

\subsection{Medical education resources are insufficient and unbalanced}

(1) The investment in medical education is relatively insufficient. The main problems are as follows: the financial investment of some remote comprehensive universities is insufficient. The average charge (tuition) standard of medical students is low. The school's own income generating ability is weak, and the capital investment is lack of performance appraisal. What's more, the school's internal teachers are insufficient; the teaching facilities are not updated enough; the specialty settings are repeated; the idle and waste of resources are prominent, and so on. (2)The allocation of health human resources is unbalanced. It mainly includes that the total number of licensed doctors in some places is insufficient; the distribution of clinical medical professionals is unbalanced, and the professional supply is in short supply; the distribution of medical and health resources is extremely unbalanced between regions, especially between urban and rural areas; the employment in urban areas is difficult, and the talents in remote and poor areas and grass-roots units are scarce.

\subsection{The orientation and mode of talent training are not suitable for the social needs}

(1) The orientation of personnel training is not clear. In the past, most of them paid attention to the training of specialized personnel for large and medium-sized urban medical and health institutions. The training of general practitioners is ignored. Even if there are talents "landing" at the grassroots level, whether they can stand still remains to be seen. (2) Personnel training mode is relatively single. It is mainly manifested in the single teaching mode, the solidification of curriculum setting, the emphasis on result oriented assessment methods and so on. (3) The adaptability of talent training to social needs is not enough. Medical students' practical ability and skill training is not in place, and humanistic quality education is weakened in the training process, which is difficult to meet the social needs.

\section{Reform And Development Of Medical Education In Comprehensive Universities In The New Era}

\subsection{Implementing the special evaluation of medical education collaboration to ensure the implementation of medical education collaboration policy}

(1) At the national level, we should improve the top-level design, carry out the special supervision and evaluation work of medical education cooperation by various departments, and promote the implementation of medical education cooperation. (2) Establishing a national data platform for medical education and use big data to monitor the development of medical education. (3) Exploring the long-term mechanism of teaching evaluation in comprehensive universities, and forming a complete "closed-loop" 
operation mechanism of quality assurance. At the same time, we should consider the linkage between the school's investment in affiliated hospitals and the contribution of affiliated hospitals to the school's medical education.

\subsection{Improving the management system of medical education in comprehensive universities and establishing a community of medical education and research}

(1) A comprehensive university can consider setting up a relatively independent management entity to undertake substantive management functions, specially implement the management of medical education, coordinate the relationship among schools, medical colleges and affiliated hospitals, strengthen the research, coordination and guidance on the development of affiliated hospitals, improve the service function of functional departments for affiliated hospitals, and promote the cross integration of medical disciplines and other disciplines. (2) Coordinating the cooperation among affiliated hospitals. The establishment of new medical institutions should meet the needs of national health education planning and long-term evaluation. (3) Building a community of medical education and research. From the management concept, we should change the old idea of emphasizing medical treatment and neglecting teaching, firmly establish the concept of "student-centered", put the medical teaching and research work in the same position, and strive to achieve the goal of " $1+1+1>3$ ". The teaching performance of clinical teachers should be included in the evaluation system, and the requirements for teaching work should be strictly implemented in the evaluation and employment of clinical teachers with double professional titles; the teaching remuneration should be reasonably distributed to encourage clinical teachers; the construction of medical teaching and research community should be considered to realize the sharing of all kinds of teaching resources.

\subsection{Increasing investment in medical education and realizing balanced allocation of health human resources}

(1)The central finance should increase the subsidies, support and assistance to the universities in the central and western regions to promote the balanced and high-quality development of medical education. (2)In view of the high cost of medical education, the local government can gradually increase the proportion of medical education in the total investment of education funds by scientifically calculating the cost of medical education, so as to achieve the proper ratio of GDP. We should consider raising the standard of average student fees (tuition), and taking the average student funding of local government for medical education as an important indicator of the examination and approval of medical majors. (3) At the school level, the school should establish a professional early warning mechanism, timely adjust the professional structure, improve teaching facilities and conditions, and avoid repeated construction and blind investment in professional construction. (4)The affiliated hospitals and other teaching hospitals shall allocate a certain proportion of funds from medical income for clinical teaching expenses. (5) Stimulating the endogenous power of colleges and universities, gathering the entrepreneurial power of alumni, and increasing the social donation and fund-raising efforts. (6) Building the "plateau" and "peak" of medical education in the central and western regions, make up for the 
shortcomings of medical education in economically underdeveloped areas, promoting the implementation of "Rural Revitalization Strategic plan" in the field of rural health services, enhancing the working level of "health gatekeepers" at the grassroots level, and providing "Two-way Referral" services. Through carrying out health counterpart support and targeted poverty alleviation, doctors can benefit patients in remote areas.

\subsection{Innovating the training mode of medical talents and improving the adaptability to social needs}

(1) Designing the orientation of medical personnel training. We should optimize and adjust the curriculum and teaching content, implement early contact with clinical practice, early contact with scientific research and social practice, increase the practice links in community health service centers, township health centers and other primary medical and health institutions, improve the medical students' ability to diagnose and treat common diseases, frequently occurring diseases and endemic diseases, and cultivate high-quality specialists and high-level general practitioners in the new era. (2) Based on "Excellent Doctor $2.0^{\prime \prime}$ as an opportunity to promote curriculum integration, comprehensive academic evaluation combining formative assessment should be carried out, and the self-learning mode of medical students will be explored. (3) Insisting on breaking the barriers between basic teaching and clinical teaching, and making early clinical education run through the whole process of medical training. (4) In the residential training, It should continue to strengthen the guidance of general practice, and give policy support to medical students who work at the grassroots level. (5) Implementing the admittance system of clinical teaching base, evaluating the teaching hospitals according to the same standard, paying attention to the career planning education of senior medical students, and guiding them to establish the practical consciousness of "only participating in clinical practice can better realize the dream of postgraduate entrance examination and employment". (6) Giving full play to the role of think tanks or listen to the suggestions of education evaluation institutions to determine the future standards to measure medical talents and meet the social needs[12-14].

\section{Conclusion}

Our findings demonstrate that there is a long way for comprehensive university to improve its quality of medical education. The reform and development of medical education need to further improve the toplevel design, and obtain the understanding and support of government agencies, school administrators, teachers, students, medical institutions and enterprises and other stakeholders [15]. A comprehensive university should consider putting medical personnel training in the vision of Health China construction. Under the guidance of the national macro policy of holding high-level undergraduate education, we should persist in problem-oriented principle and make efforts to reform. Through the ideological and practical work of medical education, we should use the internet to promote the sharing of educational resources among schools and form a synergy in medical education. Only in this way can we realize highquality development of medical education in the new era.

\section{Abbreviations}


CPC: Communist Party of China; MOOC: Mass open online course; GDP: Gross Domestic Product.

\section{Declarations}

\section{Acknowledgements}

Not applicable.

\section{Authors' contributions}

All co-authors listed below have contributed signifcantly, agree with the content of the manuscript, and have approved the manuscript for submission. LS conducted research management, study design, data collection and interpretation, review, and proofreading of the article. SH performed literature review, writing and editing the manuscript, creating tables. CL performed literature review, writing the manuscript.

\section{Funding}

This research is sponsored by the Key Project of Education Science Planning of Heilongjiang Province, China (GJB1421170).

\section{Conflicts of Interest}

The authors declare no conflict of interest.

\section{Availability of data and materials}

The datasets used and/or analyzed during the current study available from the corresponding author on reasonable request.

\section{Ethics approval and consent to participate}

Not applicable.

\section{Consent for publication}

We declare that no individual person's data was mentioned in the article.

\section{Competing interests}

We declare that there are no conflicts of interest.

The presented article is an original work, which has not been submitted to other journals.

\section{Author details}


${ }^{1}$ Medical Department, Jiamusi University, Jiamusi, 154007, China. ${ }^{2}$ School of Foreign Language, China University of Petroleum, Qingdao, 266580, China. ${ }^{3}$ Shanghai Center for Research in English Language Education, Shanghai International Studies University, Shanghai 200083, China.

\section{References}

1. Huiqing Lin. Serving Health China construction and promoting medical education reform and innovation [J]. China Higher Education, 2018 (11): 4-5.

2. Xiaoguang Shi, Huaqin Cheng, Hongbin Wu. Policy significance, demands and ideas of the new round of medical education reform in China [J]. China Higher Education, 2018 (Z3): 61-63.

3. Higher Education Steering Committee of the Ministry of Education. National standard for undergraduate professional teaching quality of ordinary colleges and universities [M]. Beijing: Higher Education Press, 2018:648-656.

4. Yang Ke. Reorientation of China's medical education reform in the 21st century [M]. Beijing: Peking University Medical Press, 2014:110-113.

5. Compilation group of this book. Guidance book of the report of the 19th National Congress of the Communist Party of China [M]. Beijing: People's Publishing House, 2017:1-69.

6. Yuanhang Song. Development and management system reform of medical education in comprehensive universities [J]. Chinese Journal of Medical Education, 2013, 33 (1): 13-15,36.

7. Shutao Peng, Jinhuan Shi. Discussion on medical education management mode of comprehensive university under the strategy of medical education collaboration [J]. Chinese Journal of Medical Education, 2018, 38 (4): 491-494.

8. Hongbin Qiu, Hanjun song. Thoughts and countermeasures on deepening the reform of medical education in comprehensive universities [J]. Chinese Journal of Medical Education, 2015,35 (6): 816818.

9. Xiaobo Wang, Qi Wang. Paying too much attention to microcosmic, medicine may go astray [EB/OL]. (2018-03-02)[2018-03-11]. http://www.jjckb.cn/2018-03/02/c_137010050.htm.

10. Bell IR, Caspi O, Schwartz GE, et al. Integrative medicine and systemic outcomes research: issues in the emergence of a new model for primary health care. Arch Intern Med, 2002,162(2):133-140.

11. Daiming Fan. My opinion on integrated medical education [J]. Negative, 2018,9 (1): 1-8.

12. Xianghua Wang, Xilin Zhang. The dilemma and Countermeasures of the third party evaluation of higher education in China from the perspective of new institutionalism[J]. Higher Education Research, 2018 (6):36-41.

13. Zhiyu Ni, Feng Cong, Hongjie Wang, et al. Exploration and Reflection on the reform of medical training in Comprehensive Universities[J]. China Higher Education Research,2020(7):87-92.

14. Dunrong Bie. New opportunities and new directions for the development of medical colleges in the new era[J].China Higher Education Research,2019(4):64-67. 
15. Xiao Luo. Analysis on the Construction of Management System of First-class University Medical College Based on the Perspective of Medical Education[J].China Medical Education Technology, 2019,33(1):19-22. 